\title{
Selection of Rapid Prototyping Technology Using an ANP Based Approach
}

\author{
Vineet Kumar ${ }^{1}$, Lalit Kumar ${ }^{2}$, Abid Haleem ${ }^{3}$ \\ ${ }^{1,2}$ Research Scholar, Department of Mechanical Engineering, Jamia Millia Islamia, New Delhi, INDIA \\ ${ }^{3}$ Professor, Department of Mechanical Engineering, Jamia Millia Islamia, New Delhi, INDIA
}

\begin{abstract}
Multi-criteria decision making Analytical Network Process Approach (ANP) is used in selection of Rapid Prototyping technology for University/Institute for performing research work because buyer may has low degree of experience in decision making with respect to machines. A frame work is developed by considering qualitative and quantitative attributes in the selection of rapid prototyping machine. This paper represents the relationship among the qualitative and quantitative attributes. For validity of framework a Sensitivity analysis is also done to analyse the effect of weight age which may be varies according to expert experience.
\end{abstract}

Keywords: Rapid Prototyping, Analytic network process, Sensitivity analysis, machine selection, Benchmarking.

\section{Introduction}

Rapid prototyping processes belongs to the generative or additive production processes. In contrast to abrasive or subtractive processes such as lathing, milling, drilling, grinding, eroding, and so forth in which the form is shaped by removing material, in rapid prototyping the components is formed by joining volume elements.

In strict sense, rapid prototyping process are therefore $21 / 2 \mathrm{D}$ process that is stacked up $2 \mathrm{D}$ contours with constant thickness. The layer is shaped in $\mathrm{x}-\mathrm{y}$ plane two dimensionally. The third dimension results from single layers being stacked up on top of each other, but not as a continuous $\mathrm{z}$ - coordinate. The models are therefore three dimensional parts, very exact on the build plane $x-y$ direction and owing to the described procedure the stepped in the $\mathrm{z}$ - direction whereby the smaller the $\mathrm{z}$ - stepping is, the more the model looks like the original.

The special characteristic features of rapid prototyping processes are that the physical models are produced directly from computer data. In principle it is thereby unimportant where the data are provided long as they describe a 3D volume completely. Data from CAD design, from the processing of measurements and reverse engineering or other measurements computer tomography (CT), magnetic resonance tomography (MRT) may be used equally well.

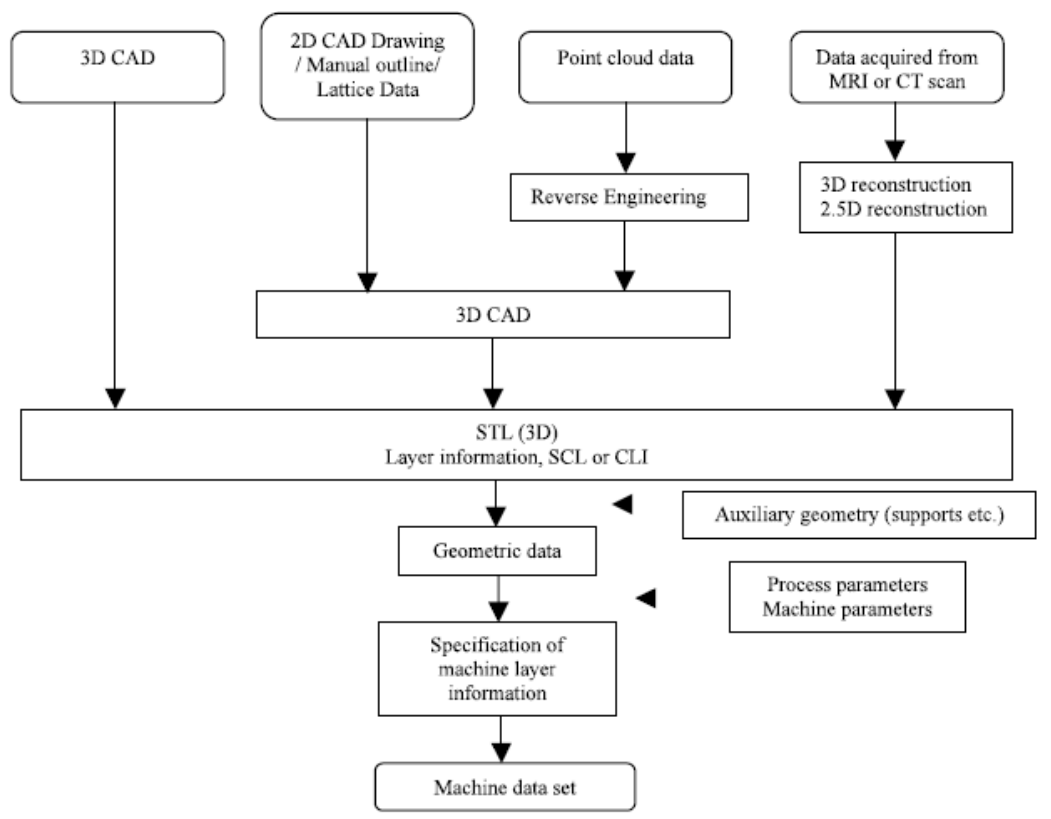

Fig. 1.Generalized illustration of data flow in RP (after Gebhardt, 2003) 


\subsection{Steps in RP Technology}

1.1.1. Design and development of CAD model

1.1.2. Slicing the CAD model

1.1.3. Sliced thin layers saved in .STL file format.

1.1.4. Define support

1.1.5. Start model for printing in $\mathrm{z}$ direction according to defined orientation, thickness, speed, flow rate etc.

1.1.6. Post processing/finishing and the joining processes.

\subsection{The STL Format}

1.2.1. The STL is an abbreviation for "Standard Triangular Language".

1.2.2. Through this software, the developed CAD model is converted into the form of millions of small triangles.

1.2.3. This later helps in storing and conversion of data.

\subsection{Major RP Technology}

1.3.1 LOM Laminated object manufacturing in which material is filled layer by layer.

1.3.2 SLA (Stereo lithography technique )

1.3.3 FDM (Fused deposition modeling).

1.3.4 SLS (Selective laser sintering)

1.3.5 Thermo jet process.

1.3.6 3D Printing

1.3.7 Ballistic Particle Manufacturing (BPM)

Some of the technologies are discussed here.

\subsection{Fused Deposition Modelling}

Scott Crump president and CEO of Stratasys developed the fused deposition Modelling Technology in 1988 and patent was awarded in the US in 1992. In this technology thermal energy source is used to melt the feed wire of raw material at the nozzle tip. In this a spool of thermoplastic filament is fed through roller in to a heated FDM extruded head the $\mathrm{x}$ and $\mathrm{y}$ movement are controlled by a computer so that the exact outline of each section of the prototype is obtained. The nozzle is moved over the base plate as the feed wire passes through the nozzle it melts only to harden again immediately as it touches the layer below.

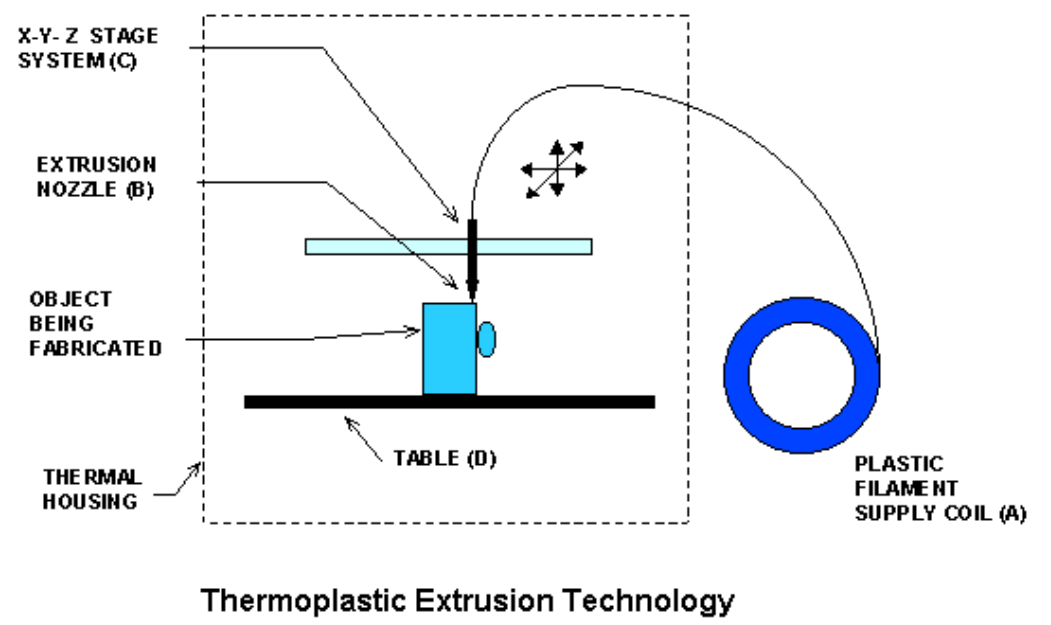

Fig. 2.Process of Fused Deposition Modelling (Source: IJAET, Vol.II, 2011, pp-.435-448)

\subsection{Selective Laser Sintering}

Selective Laser Sintering (SLS) developed by Carl Deckard at University of Texas. SLS was patented in 1989. In this technology a laser energy source is used to fuse powder materials such as nylon, elastomeric, metal in to a solid object. Laser energy source fused powder in required pattern on the platform, than this platform lowered according to layer thickness, after that a roller is used to maintained the new layer level of powder on first layer now regain laser energy is used to sintered the powder on first layer in required pattern. In this way process is repeated until whole parts is completed. 


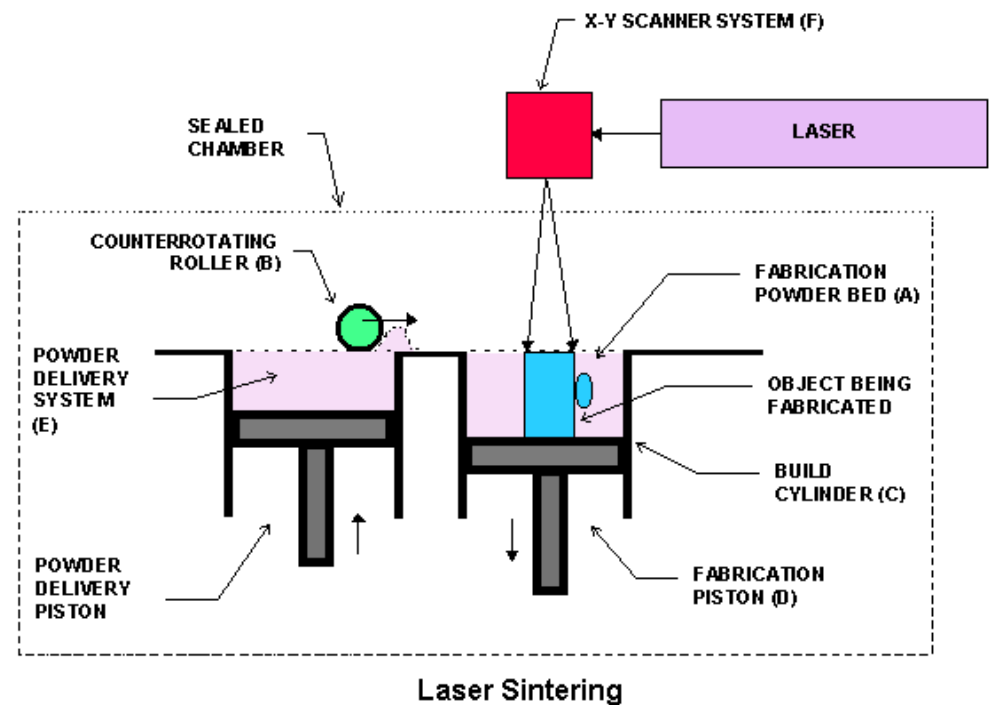

Fig. 3.Process of Selective Laser Sintering (Source: IJAET, Vol.II, 2011, pp-.435-448)

\subsection{Three Dimension Printing}

Three dimensional printing invented and patented at the Massachusetts Institute of technology (MIT). Z Corporation first developed and commercialized its printer Z 402 based on three dimensional printing Technologies. Three dimensional printing similar to SLS but in this technology at the place of Laser Source a layer of resin is used. In this technology first collect powder of required material with specific grain size and spread it on the table and after that layer of powder levelled by roller according to required thickness, than a layer of resin spray through nozzle in given pattern, then table lowered according to thickness of layer, then regain a layer of powder spread on it and rolled, levelled and spray resin by head in required pattern to stick powder with lowered layer. In similar way this process is repeated until the parts is completed.

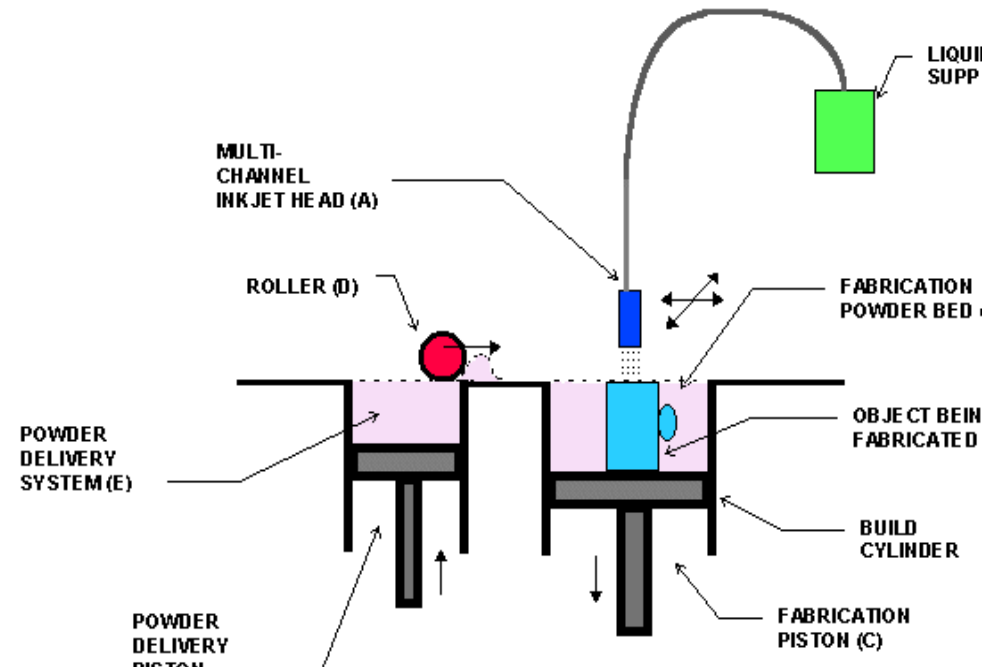

Fig.4. Process of three dimensional printing (Source: IJAET, Vol.II, 2011, pp-.435-448)

\section{Analytical Network Process}

The selection of rapid prototyping machine is very complex task due a lot of models with different attributes are available in the market. So due to lack of low previous experience about technology and high machine cost it is very difficult to select machine. In this paper A Frame work is developed by considering some specific criteria and used ANP approach for selection.

A researchers had used a Frame work by considering criteria like Price, Office friendliness, item characteristics, variety, cost and time and had applied AHP Techniques for decision making on 20 various models for ranking [1].

One researches had used A Frame work by considering criteria low cost, short lead time, better accuracy, good surface finish, sufficient strength ,Aesthetic and sub criteria like Shape complexity, material 
,surface finish, dimensional accuracy and layer thickness for rapid tooling selection for metal casting using QFD-ANP methodology [2].

One researches had given a comparison on rapid tooling techniques based on tool life, tool development life and cost of tool development [3].

\subsection{Analytic Network Processes (ANP)}

Thomas L. Saaty (born 1926 in Mosul, Iraq) is an American mathematician Professor at the University of Pittsburgh. He is the inventor, architect, and primary theoretician of AHP, a decision-making framework used for large-scale, multiparty, multi criteria decision analysis, and of ANP, Its generalization to decisions with dependence and feedback.

The Analytic Network Process (ANP) is a general theory of relative measurement used to drive composite priority ratio scales from individual ratio scales that represent relative measurement of the influence of elements that interact with respect to control criteria. Through its super matrix whose elements are themselves matrices of column priorities? The ANP captures the outcome of dependence and feedback within and between clusters of elements. The Analytic Hierarchy Process (AHP) with its dependence assumptions on clusters and elements is a special case of the ANP. The ANP provides a general framework to deal with decisions without making assumptions about the independence of higher level elements from lower level elements, and about the independence of the elements within a level. In fact the ANP uses a network without the need to specify level as in a hierarchy.

ANP is a Coupling of two parts.

(1) The First consist of a control hierarchy on network of criteria and sub criteria that control the interactions

(2) The Second is a network of influence among the elements and clusters. The network varies from criteria to criteria and a different super matrix of limiting influence is computed for each control criteria.

\subsection{Comparison AHP and ANP}

The AHP consists of one goal, some criteria and alternatives, which are arranged in a hierarchy structure where the lower level elements influence on higher level elements.

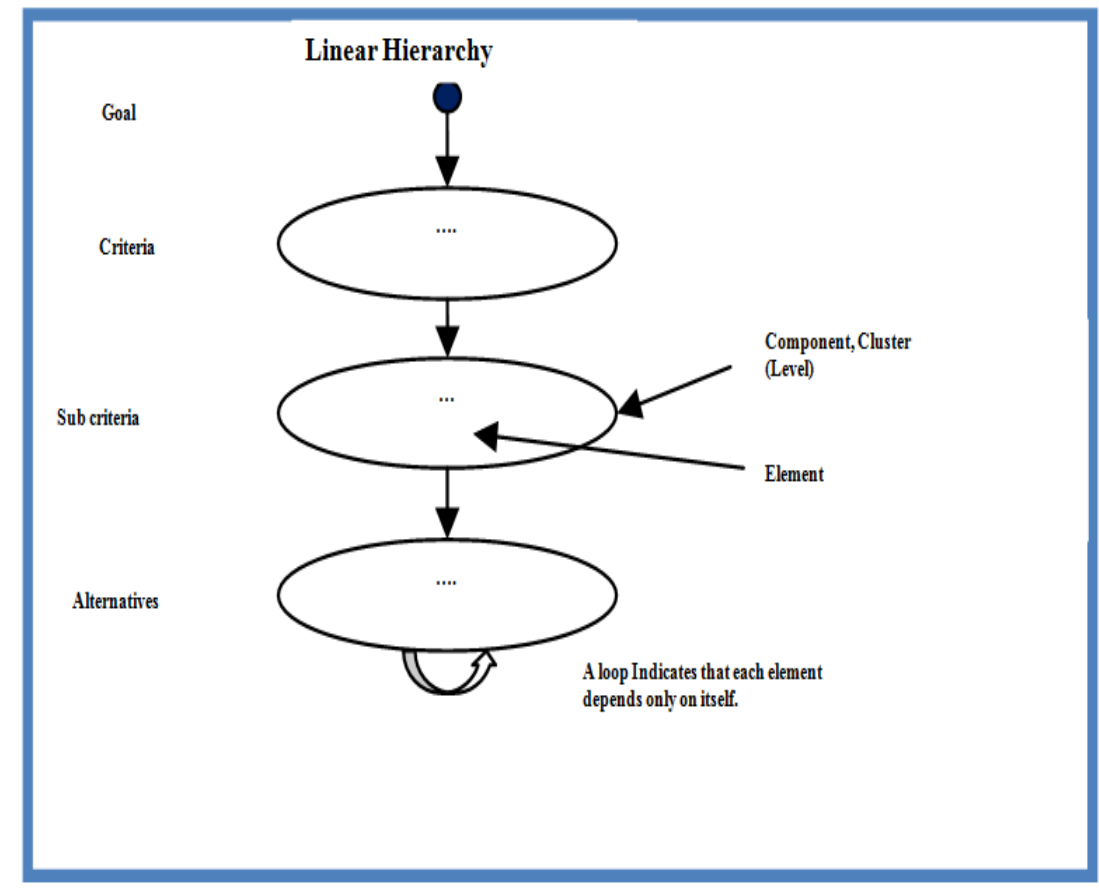

Fig.5. Hierarchy Structure of AHP

Many decision problems cannot be structured in a hierarchy because they involve dependence between the alternatives, dependences of the criteria that belong to a same level or dependence of higher level elements on lower level elements, besides the mentioned relation. This concern motivated Thomas Saaty to develop the ANP, which makes possible a natural development of the problem because it does not impose a structure a network can be extended in all directions. 


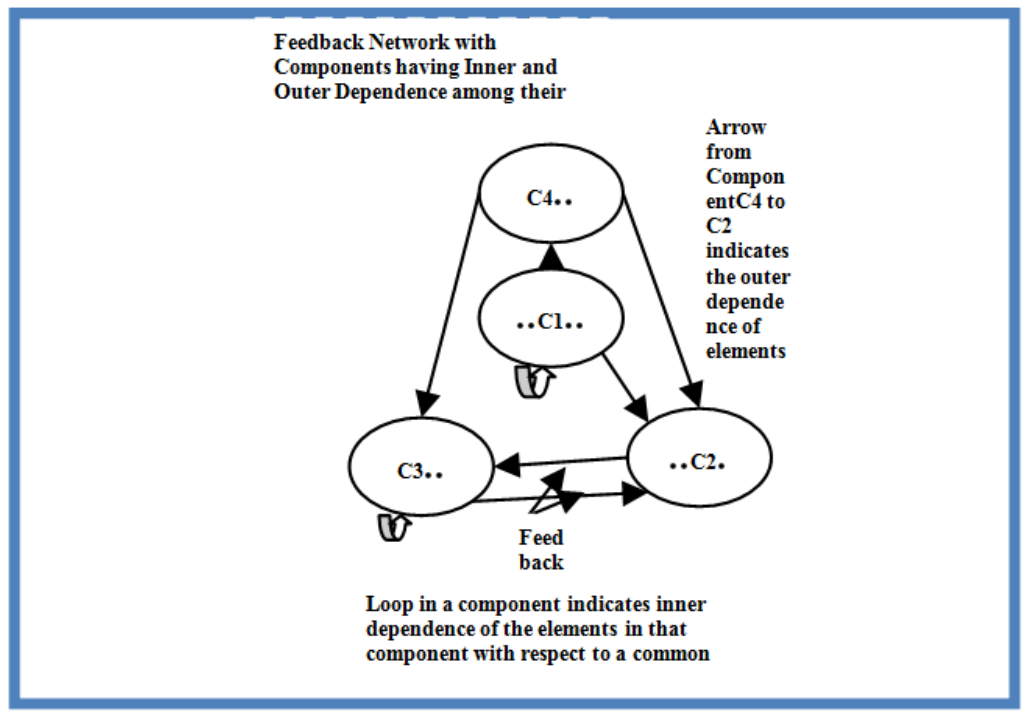

Fig.6.Network Structure of ANP

The Analytic Network Process (ANP) methodology has been selected to find the Organizational Performance.

\section{Methodology}

The Analytic Network Process (ANP) methodology has been used to find the Organizational Performance. The various steps involved are discussed below.

\section{Step1: Model development and problem formulation}

ANP model has been developed based on the criteria identified. The criteria have been classified in to various levels for instance determinants, dimensions, and enablers. Generally the higher level criteria or the determinants play a crucial role in strategic decision making thus the criteria of customer perspective, financial perspective, market competitiveness, and social responsibility of measurement of organizational performance are grouped in higher level. In middle level criteria are named as dimensions, these are market response, cost control, information driver, and corporate social responsibility. The third level criteria in the ANP model are termed as enablers. The enablers supports the respective dimensional criteria as well as other enablers hence interdependencies persist in among the enablers. The developed model in accordance to other models found in the literature (Meade and Sarkis, 1999; Jharkharia and Shankar, 2007).

\section{Step2: Pair-wise comparison matrices between component/attribute levels.}

The Fundamental Scale used for the judgments is given in table. Judgments are first given verbally as indicated in the scale and then a corresponding number is associated with that judgment. The vector of priorities is the principal eigenvector of the matrix. This vector give the relative priority of the criteria measured on a ratio scale. That is, these priorities are unique to within multiplication by a positive constant. However, if one ensures that they sum to one they are then unique and belong to a scale of absolute numbers.

Table 1. Saaty's Scale (1980)

\begin{tabular}{|ll|}
\hline \multicolumn{2}{|l|}{ Fundamental Scale } \\
\hline 1 & equal importance \\
\hline 3 & moderate importance of one over another \\
\hline 5 & strong or essential importance \\
\hline 7 & very strong or demonstrated importance \\
\hline 9 & extreme importance \\
\hline $2,4,6,8$ intermediate values \\
\hline Use reciprocals for inverse comparisons \\
\hline
\end{tabular}

Pair-wise comparison matrix

$$
\mathrm{A}=\left[\begin{array}{cccc}
a_{11} & a_{12} & \cdots & a_{1 n} \\
a_{21} & a_{22} & \cdots & a_{2 n} \\
\vdots & \vdots & \ddots & \vdots \\
a_{n 1} & a_{n 2} & \cdots & a_{n n}
\end{array}\right] \mathrm{N} \text { is counted for the hierarchy of matrix. } \mathrm{a}_{\mathrm{ij}}
$$


The principal diagonal contains all comparisons of an alternative with itself.

\begin{tabular}{|l|l|l|l|}
\hline $\mathbf{1}$ & & & \\
\hline & 1 & & \\
\hline & & 1 & \\
\hline & & & 1 \\
\hline
\end{tabular}

Principal diagonal of a comparison matrix

To fill up the upper triangular matrix is using the following rules.

1. If the judgment value is on the left side of 1 , we put the actual judgment value.

2. If the judgment value is on the right side of 1 , we put the reciprocal judgment value

Step 3: Standardization of the pair wise comparison matrix

$\mathrm{A} 1=\left[\begin{array}{cccc}a_{11}^{\prime} & a_{12}^{\prime} & \cdots & a_{12}^{\prime} \\ a_{21}^{\prime} & a_{22}^{\prime} & \cdots & a_{2 n}^{\prime} \\ \vdots & \vdots & \ddots & \vdots \\ a_{n 1}^{\prime} & a_{n 2}^{\prime} & \cdots & a_{n n}^{\prime}\end{array}\right]$, and $a_{i j}{ }^{\prime}=\frac{a_{i j}}{\sum_{i=1}^{n} a_{i j}}$ for $\mathrm{i}, \mathrm{j}=1,2, \ldots \ldots \ldots \ldots \ldots$,

Step 4: Calculate the $W$ of the eigenvector and the $\square_{\max }$ of the eigenvalue

$\mathrm{W}=\left[\begin{array}{l}w_{1} \\ w_{2} \\ \vdots \\ w_{n}\end{array}\right]$, and $w_{i}=\frac{\sum_{i=1}^{n} a_{i j}^{\prime}}{n}$ for $\mathrm{i}=1,2, \ldots \ldots, \mathrm{n}$,

New Matrix W'

$\mathrm{W}^{\prime}=\mathrm{AW}=\left[\begin{array}{l}w_{1}^{\prime} \\ w_{2}^{\prime} \\ \vdots \\ w_{n}^{\prime}\end{array}\right]$, and $\lambda_{\max }=\frac{1}{n}\left(\frac{w_{1}^{\prime}}{w_{1}}+\frac{w_{2}^{\prime}}{w_{2}}+\frac{w_{3}^{\prime}}{w_{3}}+\ldots \ldots \ldots .+\frac{w_{n}^{\prime}}{w_{n}}\right)$,

Step 5: Calculate Consistency Ratio

$\mathrm{CI}=\frac{\lambda_{M A X}-n}{n-1}$, and $\mathrm{CR}=\frac{C I}{R I}$

\section{Step6: Super matrix formation and analysis}

The super-matrix allows for a resolution of interdependencies that exist among the elements of a system. It is a partitioned matrix where each sub-matrix is composed of a set of relationships between and within the levels as represented by the decision-maker's model. The super-matrix M, may be prepared for the relative importance measures for each of the enablers for the customer perspective determinant. The elements of the super-matrix have been imported from the comparison matrices of interdependencies.

In the next stage, the super-matrix is made to converge to obtain a long-term stable set of weights. For convergence to occur, the super-matrix needs to be column stochastic. In other words, the sum of each column of the super-matrix needs to be one. Raising the super-matrix to the power $2^{\mathrm{k}+1 \text {, }}$ where $\mathrm{k}$ is an arbitrarily large number, allows convergence.

\section{Step7 Selection of best alternative}

The desirability index $\mathrm{D}_{\mathrm{ia}}$ can be calculated for defined alternatives ' $\mathrm{i}$ ' and determinant 'a' according to Meade and Sarkis, 1999.

$$
D_{i a}=\sum_{j=1}^{J} \sum_{k=1}^{k_{j a}} P_{j a} A_{k j a}^{D} A_{k j a}^{I} S_{i k j a}
$$


Where $P_{j a}$ is the relative significant weightage of dimensions 'j' on the defined determinant ' a', $A_{k j a}^{D}$ is the relative importance weight for attribute enabler ' $\mathrm{k}$ ', dimension ' $\mathrm{j}$ ' and determinant ' $\mathrm{a}$ ' for the dependency (D) relationships between enabler's component levels, $A_{k j a}^{I}$ is the stabilized relative importance weight for attribute enabler ' $k$ ' of ' $j$ ' dimension in the determinant ' $a$ ' for interdependency (I) relationships within the attribute enabler's component level, $S_{i k j a}$ is the relative impact of alternatives 'i' on attribute enabler ' $k$ ' of dimension ' $j$ ' for determinant ' $a$ '.

$K_{j a}$ is the index set of attribute enablers for dimension ' $\mathrm{j}$ ' of the determinant 'a', 'J' is the index set for the dimension ' $\mathrm{j}$ '.

$D_{i a}$ is the Desirability index and their normalized values Dian for the compatibility determinant 'a', $C_{a}$ is comparison of determinants.

$O W I_{i}=\sum_{a} D_{i a} C_{a}$

Normalized weightage Index $=\frac{O W I_{i}}{\sum O W I_{i}}$ column.

ANP as a crucial tool, it is necessary to identify its advantages and disadvantages fitting this research, Ravi, Ravi and Tiwari(2005) summarized the advantages and the disadvantages of ANP as follows(Ravi et al.,2005).

- The pair-wise comparisons under consideration can only be performed subjectively, and hence the accuracy of their results depends on the expertise of the expert involved in the area concerned.

\section{Decision Making Frame Work}

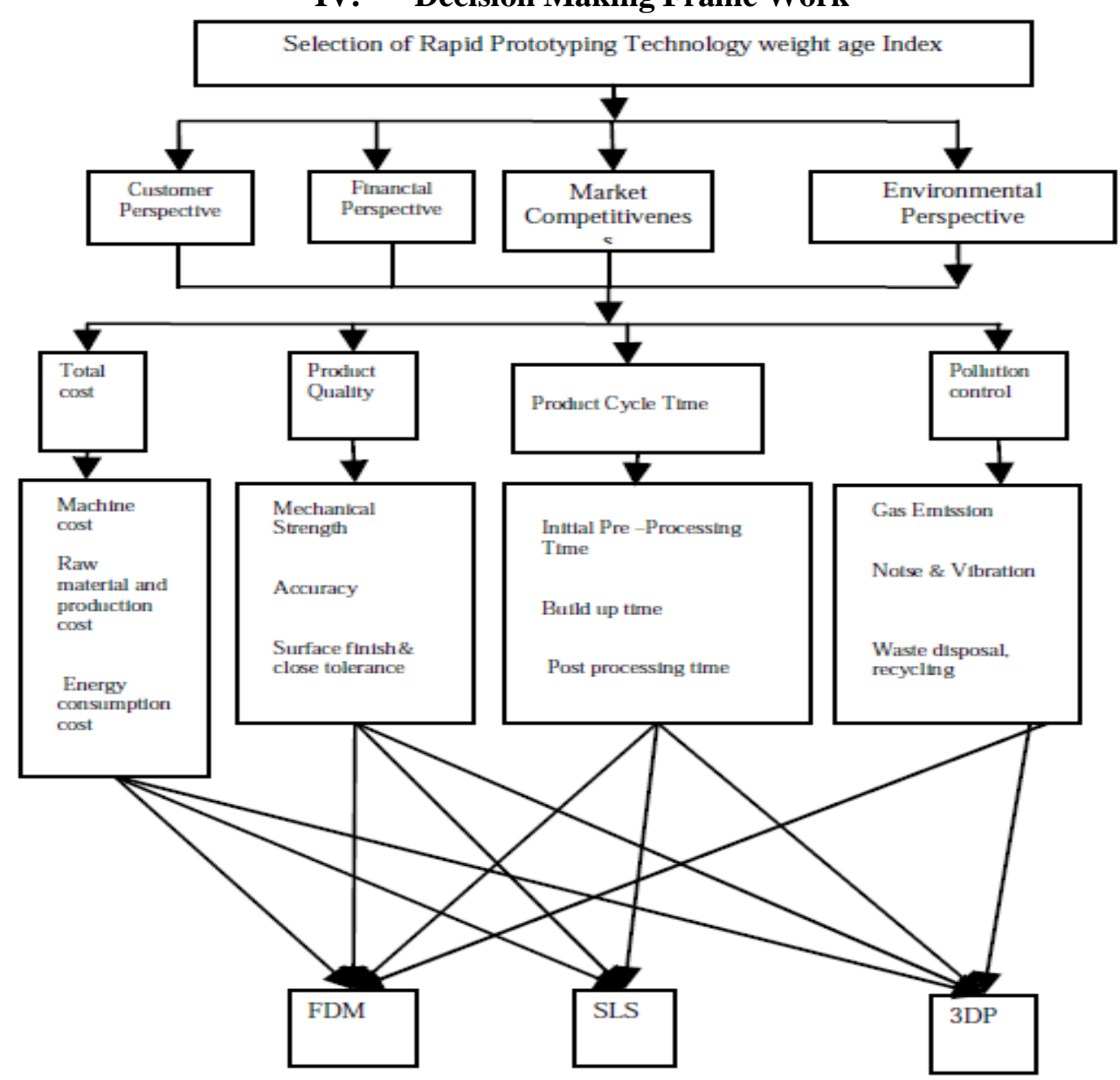

Fig. 7.ANP Based Model for selection of best Alternative RP Technology 


\section{Conclusion \& Future Work}

In this paper a framework is developed by considering three rapid prototyping technologies. An ANP methodology is adopted for decision making through ranking. In future the pair wise comparison matrices will be developed for determinants, dimensions, enablers, alternatives. This methodology integrates various determinants, dimensions, enablers and alternatives and also gives their relationships and interdependencies along hierarchies by considering quantitative as well as qualitative characteristics. The sensitivity analysis and normalization will be done to find the best alternate.

\section{References}

[1]. Saaty, T. L., Decision making with the analytic hierarchy process, Int. J. Services Sciences, Vol. 1, No. 1, 83-98, 2008.

[2]. Saaty, Thomas L.,Decision making-the Analytic Hierarchy and Network Processes (AHP/ANP). Journal of Systems Science and Systems Engineering, Vol.13, No 1,1-31,2004.

[3]. Saaty, Thomas L.,Fundamentals of the Analytic Network Process, International Symposium on the Analytic Hierarchy Process, 1999

[4]. Kaplan, R.S.,Norton,D.P, The balanced scorecard: measures that drives performance, Harvard Business Review, Vol. 70, 71$79,1992$.

[5]. Agarwal, A.; Shankar, R.; Tiwari, M.; Modeling the metrics of lean,agile,and leagile supply chain: An ANP-based approach. European Journal of Operational Research 173, 211-225, 2008.

[6]. Qureshi, M. N.; Kumar, Pradeep; Kumar, Dinesh; Selection of Transportation Company: An analytic network process (ANP) approach. ICFAI Journal of Supply Chain Management; Vol. 6 Issue 2, 26, 2009.

[7]. Sharma, M.J.; Moon, I.;Bae,H., Analytic hierarchy process to assess and optimize distribution network, Applied Mathematics and Computation 202,256-265,2008.

[8]. Lokesh, K.; Jain, P.K. , Selection of Rapid Prototyping Technology, Advances in Production Engineering \& Management, Vol$2,75-84,2010$

[9]. Brown, R.; Stier,K., Selecting Rapid Prototyping Systems,Journals of Industrial Technology, Vol. 18,1-8,2002.

[10]. Chandramohan, D.;Marimuthu,K., Rapid Prototyping/Rapid Tooling -A over view and its applications in orthopedics, IJAET,Vol. 2,435-448,2011.

[11]. Lee, C.S.; Kim, S.G.;Kim,H;Ahn,S.,Measurement of anisotropic compressive strength of rapid prototyping parts, Journals of Materials Processing Technology 187-188,627-630,2007.

[12]. Huang, S.;Liu.P; Mokasdar,A., Additive manufacturing and its social impact: a literature review,International Journal AdvanceManufacturing Technology, 67:1191-1203,2013.

[13]. Meade,L.;Presley,A., R\&D Project Selection using the Analytic Network Process, IEEE, Vol.49, 59-66, 2002.

[14]. Www.phillipsplastics.com

[15]. Hernandez,A.;Wong,K., A review of additive Manufacturing, ISRN Mechanical Engineering, 208760, 1-10,2012.

[16]. Yusoff,W.;Badri,Z.;Masri,Z. Hussin,Z. Benchmarking the Rapid Prototyping Machines (RPM) for Education purpose using Quality function development, 1-17

[17]. www.hansergardner.com

[18]. Shahrabi.,M.; Javadi, M., Selection of Rapid Prototyping Process Using Combined AHP and TOPSIS Methodology, International Journal of Information Science and System, 3(1) 15-22,2014.

[19]. http://www.isc.senshu

[20]. MATLAB 2010a

[21]. Vijay.P.;Danish,P;Rajesh,K, Critical Parameters Effecting the Rapid Prototyping Surface Finish,Journal of Mechanical Engineering and Automation, 1(1),17-20,2011.

[22]. Choi,S.;Samavedam,S., Modelling and Optimization of Rapid Prototyping,Computers in Industry, 39-53,2002.

[23]. Wong,K;Hernandez,A., .A Review of Additive Manufacturing,IRSN,208760, 2012.

[24]. Mahindru,D;Mahendru,P., Review of Rapid Prototyping-Technology for the Future,global journal of computer science and technology,vol-13,2013.

[25]. Onuh,S;Yusuf,Y., Rapid prototyping technology: Applications and benefits for rapid product development, 10,301-311,1999.

[26]. Sugavaneswaran,M;Arunmaikkannu,G.,Modelling for randomly oriented multi material additive manufacturing component and its fabrication, Materials and Design, 779-785,2004. 